\title{
Eu (não) sou leitor: contradições de leitores jovens sobre a leitura e de si enquanto leitores
}

DOl: http://dx.doi.org/10.21165/el.v49i3.2730

\section{Rafael Borges ${ }^{1}$}

\section{Resumo}

O presente trabalho tem por objetivo empreender uma análise de declarações sobre a leitura geradas a partir do desenvolvimento de questionários com 101 estudantes e entrevistas com mais 20, todos da Escola Agrícola de Jundiaí, da Universidade Federal do Rio Grande do Norte. A partir disso, buscamos entender as contradições que apresentam no que declaram acerca da leitura de modo geral e de si como leitores. Ao longo de nossas análises, pudemos constatar que uma boa parte deles se reconhece como bons leitores em contraposição a outros que se afastam desse lugar-sujeito, ainda que realizem cursos integrais, que Ihes exigem uma intensa e extensa carga de leituras cotidianas. Essas declarações resultam em algumas contradições que acabam por constituir um campo discursivo bastante complexo, analisado com base na Análise do Discurso de linha francesa e em princípios da História Cultural do livro e da leitura. Para nós docentes, observar e analisar tais processos e dizeres se caracteriza como fundamental, pois permitem pensarmos e redimensionarmos a formação leitora crítica dos jovens na contemporaneidade.

Palavras-chave: leitor jovem; leitura crítica; EAJ/UFRN; formação de leitores.

1 Universidade Federal do Rio Grande do Norte (UFRN), Macaíba, Rio Grande do Norte, Brasil; rafaeljud@hotmail.com; https://orcid.org/0000-0001-5312-7927 


\section{Yo (no) soy lector. contradicciones de lectores jóvenes sobre la lectura y de sí como lectores}

\section{Resumen}

El presente trabajo tiene por objetivo emprender un análisis de declaraciones sobre la lectura generadas a partir del desarrollo de encuestas con 101 estudiantes y entrevistas con 20 más, todos de la Escola Agrícola de Jundiaí, de la Universidade Federal do Rio Grande do Norte. A partir de eso, nos dedicamos a entender las contradicciones que presentan en lo que declaran acerca de la lectura de modo general y de sí como lectores. Al largo de nuestros análisis, pudimos constatar que una buena parte de ellos se reconoce como buenos lectores en contraposición a otros que se alejan de ese lugar-sujeto, aunque realicen cursos integrales, que les exigen una intensa y extensa carga de lecturas cotidianas. Esas declaraciones resultan en algunas contradicciones que terminan por constituir un campo discursivo bastante complejo, analizado con base en el Análisis del Discurso de línea francesa y en principios de la Historia Cultural del libro y de la lectura. Para nosotros docentes, observar y analizar tales procesos y dichos se caracteriza como fundamental, pues permiten que pensemos y redimensionemos la formación lectora crítica de los jóvenes en la contemporaneidad.

Palabras clave: lector joven; lectura crítica; EAJ/UFRN; formación de lectores.

\section{Introdução}

Aleitura, como a concebemos aqui, parte de uma perspectiva sociocultural, ou seja, leva em conta desde o contexto de produção do escrito à sua apropriação pelo leitor, abrangendo aspectos que vão da materialidade linguística à historicidade do texto, localizado em um tempo e espaço. Sendo assim, como já é de consenso em vários campos de estudos dedicados à leitura nas últimas décadas, o ato de ler não se trata de uma prática neutra, mas carregada de valores culturais, sociais, políticos e ideológicos, intrínsecos à vida em sociedade, que é dinâmica e em suas múltiplas faces, permanecendo e se transformando constantemente. Desse modo, se as mudanças são processos constitutivos da própria vida, consequentemente também se dão no âmbito da materialidade dos objetos, bem como nos modos e gestos de leitura, refletindo nas práticas e nos gostos acerca do ler, logo, na forma como nos concebemos ou não como leitores, naquilo que entendemos como leitura legítima, a ser declarada, quantificada e, por outro lado, as que são negadas, silenciadas, tomadas como não leituras.

As representações que fazemos da leitura de modo geral e de nós como leitores se materializam e se constituem a partir de uma complexa teia discursiva de significados e significações, envolvendo tanto a singularidade do sujeito como a coletividade na qual está inserido, em uma constante luta de poder, de hierarquizações e de domínio pelas 
significações do dizer e do poder dizer certas coisas e não outras, de determinados modos e não de outros (FOUCAULT, 2014)

É fato que há muito circulam em nossa sociedade discursos nostálgicos e fatalistas sobre a leitura e o ser leitor, em especial acerca dos jovens, em que comumente se apregoa a ideia de que as gerações anteriores liam mais e melhor do que eles o fazem atualmente, pois perdem muito tempo na internet e nas redes sociais. Muito disso advém de uma concepção ocidental elitista de leitura e do ser leitor, que emergiu no final do século XVIII, ganhando força ao longo do XIX, com a ascensão da burguesia da qual somos, em partes, herdeiros (ABREU, 2001). Sendo assim, no senso comum, ao constatar a ausência ou uma presença não tão frequente como se gostaria dessas práticas e formas de ler do passado no presente, emerge o discurso de que os jovens não leem e não gostam de ler.

Essa problemática não só nos cega para as práticas de leitura empreendidas cotidianamente em nossa sociedade, por meio de uma infinidade de objetos e formas de ler inexistentes até há alguns anos atrás, como também acaba por fazer da leitura uma forma de status social, contribuindo para a elitização do conhecimento e a perpetuação de hierarquias que fomentam a produção e as desigualdades sociais.

Considerando o exposto, nosso objetivo no presente trabalho é realizar um levantamento de enunciados e discursos de jovens estudantes entre 14 e 19 anos sobre a leitura e de si como leitores, de modo a analisar suas representações gerais sobre o tema e que fazem de si como leitores. Esses dados podem contribuir para um melhor conhecimento do leitor jovem em fase escolar, facilitando o desenvolvimento de estratégias didáticas direcionadas à formação leitora crítica desse público, no contexto analisado e em outros semelhantes.

Inicialmente apresentamos a metodologia, o contexto de pesquisa e de geração dos dados, além também das teorias e principais conceitos que fundamentam nossas análises. A partir disso, desenvolvemos uma visão geral sobre o tema, para posteriormente situá-lo em suas especificidades históricas e culturais no contexto brasileiro. Toda essa ambientação do tema nos permite questionar e problematizar a naturalização dos consensos em leitura e suas implicações nas representações que fazemos do leitor jovem e, por conseguinte, que fazem da leitura de modo geral e de si como leitores, observando possíveis contradições nesses dizeres. Para tanto, utilizamos dados gerados por nós e analisados sob os conceitos da Análise do Discurso de linha francesa, com recorrência aos textos de Michel Foucault e também com base em princípios da História cultural do livro e da leitura, além de experiências empíricas em sala de aula e em pesquisas acerca do tema, empreendidas nos últimos dez anos de nossa atuação profissional. 


\section{Contextualização, metodologia e fundamentação teórica da pesquisa}

Este artigo é resultado de uma pesquisa desenvolvida junto a alunos da Escola Agrícola de Jundiaí (EAJ), da Universidade Federal do Rio Grande do Norte (UFRN), matriculados nos diferentes cursos Técnicos (Agropecuária, Aquicultura, Agroindústria e Informática) integrados ao Ensino Médio, ou seja, estudantes de período integral, que cotidianamente enfrentam uma intensa e extensa carga de leituras, aulas e disciplinas.

Os dados² que são apresentados aqui foram gerados em 2018 e em duas etapas. A primeira delas se deu junto a 101 alunos dos segundos anos, a partir de questionários ${ }^{3}$ compostos por questões objetivas (de múltipla escolha e dicotômicas "sim ou não"), que pudéssemos compará-las e quantificá-las mais facilmente. Além também de questões discursivas mais genéricas, com o intuito de empreendermos respostas mais livres, que nos permitiram estabelecer cotejamentos com vistas a averiguar a recorrência ou não de certos discursos assinalados na parte fechada do questionário com o que declararam nas questões abertas, sobre a leitura e de si como leitores.

Na segunda etapa, nos valemos de quase três horas de entrevistas, gravadas em áudio e conduzidas a partir de um roteiro semiestruturado, constituído por 9 questões. Nessa fase da pesquisa contamos com um total de 20 participantes divididos em dois grupos de cinco, dois grupos de quatro e uma dupla, isso de acordo com a disponibilidade que tinham. Esses alunos, apesar de serem de diferentes anos e cursos técnicos, compartilham entre si o fato de integrarem um grupo de leitura com encontros semanais na EAJ/UFRN, na época coordenado por nós.

Vale ressaltar que esses dois instrumentos de geração de dados foram desenvolvidos em condições diferentes. Os questionários em horário de aula, realizados via Google doc. e em computadores individuais, já as entrevistas se deram de forma coletiva e em horários extraclasse. Esses diferentes instrumentos e formas de geração de dados permite uma melhor triangulação e fiabilidade dos mesmos.

2 Tais dados foram, por diversas vezes, discutidos junto ao Laboratório de Estudos da Leitura (LIRE) e com o Grupo de Pesquisa em Aprendizagem e Ensino de Línguas (Grael), aos quais agradeço imensamente todo o apoio, porém assumo total responsabilidade pelos menos e por algum possível equívoco que venha a se apresentar.

3 Esta pesquisa foi submetida e aprovada pelo Comitê de Ética em Pesquisa com seres humanos da Universidade Federal de São Carlos sob o número de Certificado de Apresentação para Apreciação Ética (CAAE) 92752218.7.0000.5504 e do parecer 2.804.953. Sendo assim, durante a geração de dados, tomamos todos os cuidados éticos necessários e ao longo deste artigo, como é de consenso na área e também meio de resguardar a individualidade dos participantes, para as entrevistas utilizamos E (Entrevistado) e um número aleatório, já para os questionários utilizamos a sigla dos cursos de pertencimento desses alunos (Aquicultura $=\mathrm{AQ}$, Agroindústria $=$ Al, Agropecuária = AP, Informática = IF) e um número aleatório. 
Considerando a natureza dos dados gerados, os instrumentos utilizados e nossas intenções de análise, nos valemos de uma metodologia de pesquisa mista, ou seja, apoiamo-nos tanto em aspectos qualitativos como quantitativos de nossos dados, aqui, especificamente, o quantitativo servirá para embasar e dar maior consistência a nossas análises qualitativas, a partir de uma perspectiva analítica crítica dos dados gerados.

Essa metodologia nos facilita melhor entender os dados sociológicos desses alunos, como o fato de $60 \%$ deles serem advindos de escolas públicas e, em suas declarações, alegarem ter optado pela Escola Agrícola de Jundiaí devido à oportunidade de cursarem um Ensino Médio gratuito e de qualidade, capaz de permitir-Ihes uma melhor qualificação para o mercado de trabalho.

Acerca da origem familiar, a maioria dos pais possui como nível máximo de escolaridade o Ensino Médio completo, ainda que muitos não tenham alcançado essa escolaridade e alguns outros possuem ou tiveram algum acesso à graduação e pós-graduação. Em geral, trabalham como assalariados, na função de atendentes, motoristas, pedreiros, vigilantes, etc. A partir disso, e por várias outras declarações que compõem o nosso corpus, podemos afirmar que boa parte dos alunos é de origem simples, vivem em situação de vulnerabilidade social ${ }^{4}$ e visualizam no ensino público federal uma melhor oportunidade e condição de vida.

Ter esse mapeamento inicial dos alunos, ainda que de maneira breve, nos parece muito importante para entendermos, em traços gerais, o que declaram sobre a leitura e de si como leitores, pois Soares (2001, p. 21), a partir de uma pesquisa realizada com crianças em fase de alfabetização e com os pais delas, de classes sociais diferentes, constatou-se que

[...] enquanto as classes dominantes veem a leitura como fruição, lazer, ampliação de horizontes, de conhecimentos, de experiências, as classes dominadas a veem pragmaticamente como instrumento necessário à sobrevivência, ao acesso ao mundo do trabalho, à luta contra suas condições de vida.

Nesse sentido, analisamos as especificidades e as regularidades desses enunciados com base em Foucault $(2015,2014)$, mais especificamente nos valendo dos conceitos de enunciado, discurso, formação discursiva e arquivo. Esses conceitos, relacionados de

4 Conforme disposto na resolução da UFRN n² 229/2018-CONSEPE (Conselho de Ensino, Pesquisa e Extensão), em 04 de dezembro de 2018, e publicado no boletim de serviços da UFRN, n² 243, em 27 de dezembro de 2018, fls. 14, capítulo VI, art. 25: "Considera-se estudante em vulnerabilidade socioeconômica aquele que possua renda familiar per capita igual ou inferior a um salário mínimo e meio e/ou comprove situação de carência por meio de avaliação socioeconômica a partir de análise de documentos comprobatórios apresentados pelo estudante". 
maneira escalonar, apresentam desde a unidade elementar por meio da qual o discurso se manifesta, a saber, o enunciado, até uma dimensão mais ampla, que ajuda a situar histórica e culturalmente o(s) discurso(s), isto é, as formações discursivas comuns ou opostas, que o arquivo de uma época congrega; é este que estabelece, entre outras coisas, as condições de enunciabilidade dos discursos, daquilo que se mantém, do que se transforma e do que está fadado ao esquecimento, dentro de uma grande arena de lutas pela calibragem e poder dos sentidos.

Valemo-nos ainda de reflexões históricas sobre a leitura empreendidas no campo da História Cultural, principalmente a partir de Chartier (1999, 1990), baseando-nos especificamente no conceito de representação, que nos ajuda a situar essa prática no tempo e no espaço, assim como compreender as mudanças e as regularidades que a caracterizam no tempo, no espaço e nos usos, conforme as comunidades leitoras, seus interesses e suas habilidades.

A interface entre esses dois campos se estabelece por seu interesse comum pelas práticas de leitura e escrita, por suas preocupações históricas e sociais na análise dessas práticas, reconhecendo, cada um à sua maneira, o funcionamento dos discursos na sua relação com as práticas, as injunções da história sobre o que declarar ou não, de que formas fazê-lo, com base em que memórias discursivas históricas e sociais exercê-las, reproduzi-las e difundi-las.

\section{Os jovens não leem e não gostam de ler! Será mesmo?}

[...] talvez também usemos as mesmas estratégias mentais que usaram nossos pais para ler e escrever, mas está claro que os discursos de hoje, do século XXI, servem para fazer coisas diferentes. Se a televisão mudou, se os carros são muito mais sofisticados, se a cozinha se encheu de artefatos eletrônicos, também os discursos evoluíram, com as novas tecnologias, com o contato com falantes de diferentes culturas, com a explosão da investigação científica. (CASSANY, 2006, p. 9, tradução nossa ${ }^{5}$ ).

De encontro a alguns consensos nostálgicos e fatalistas sobre os jovens e a leitura, Ceccantini (2016) aborda o tema a partir de uma análise crítica dos dados levantados pela

5 No original: "[...] quizá también usemos las mismas estrategias mentales que usaron nuestros padres para leer y escribir, pero está claro que los discursos de hoy, del siglo XXI, sirven para hacer cosas distintas. Si la televisión ha cambiado, si los coches son mucho más sofisticados, si la cocina se ha llenado de artefactos electrónicos, también los discursos han evolucionado, con las nuevas tecnologías, con el contacto con hablantes de diferentes culturas, con la explosión de la investigación científica". 
$4^{\circ}$ pesquisa "Retratos da Leitura no Brasil" ${ }^{\circ}$, em que, diferente dessas representações, atesta que os jovens não só leem, mas que leem por prazer, em uma proporção e frequência maior do que a média nacional geral. Nessa mesma direção, Borges (2017) se vale do desenvolvimento de questionários com professores, nos quais afirmam que a maior dificuldade em formar leitores em língua estrangeira seria a "falta de vontade dos alunos", já que "eles não leem", "não leem nem os textos, os romances de literatura brasileira", etc. A partir disso, o pesquisador analisa esses enunciados contextualizandoos historicamente, evidenciando o seu funcionamento como instrumento de poder e de manutenção de hierarquias sociais desiguais. Em geral, essas pesquisas contemporâneas buscam não reduzir a questão a uma crise da leitura, mas antes disso olham suas conjunturas em um viés histórico, cultural, político, social e ideológico.

Essa problemática, longe de se restringir ao contexto brasileiro, também é abordada por Petit (2013), no cenário francês, em que junto a esses discursos emerge a preocupação de "como fazer para que os jovens leiam?", o que a autora critica, uma vez que a questão abre margens para acreditar que existiria um modelo de procedimentos determinados para formar leitores. Britto (2016) também abordou e refutou de forma muito pertinente essa ideia, ao tratar de alguns consensos em leitura, afırmando que não existe uma fórmula mágica, como um caminho predeterminado a ser percorrido, pois antes disso há a necessidade de olhar as condições materiais, sociais, culturais, ideológicas, entre outras, de que as pessoas possam ou não serem leitoras.

Sendo assim, é fundamental que consideremos algumas especificidades do contexto brasileiro em relação a outros países, a começar por uma democratização tardia de acesso à educação formal pela população economicamente menos favorecida, realizada de modo bastante questionável, por volta da metade do século XX. Outro ponto importante é a consolidação de um mercado livreiro também tardio, que segue ainda hoje bastante exclusivo e elitista, a começar pelos altos custos dos livros e a ausência de bibliotecas públicas pelo país, o que dificulta o acesso aos mesmos. Segundo Curcino (2014, p. 48),

No Brasil, em pleno século XXI, uma revolução da leitura parece não ter se dado ainda. Entre vários fatores, dos quais não se pode negligenciar a história política da educação, há um traço muito particular da história cultural de nosso país: os brasileiros, antes de vivenciarem uma revolução da leitura semelhante à que ocorreu no período do século XVIII ao XIX, na Europa, travaram contato com outras formas de informação e entretenimento que dispensariam, substituiriam ou concorreriam com a leitura do impresso e o papel formador dos livros, impedindo que a leitura se tornasse um hábito da grande massa populacional na obtenção de informações, de formação e de entretenimento.

6 Essa pesquisa é empreendida, principalmente, pelo mercado editorial brasileiro, a nível nacional, e toma como leitor aqueles que leram, nos últimos três meses, pelo menos um livro, em partes ou em sua totalidade. 
Em um contexto mais amplo, essa ideia de que os jovens não leem coaduna e ajuda a reforçar o discurso de que somos um país de não leitores, que não gostamos de ler. Esse imaginário que circula há várias décadas em nossa sociedade motivou uma série de pesquisas nos últimos tempos, que vem se dedicando a olhar as questões históricas dessa problemática e as suas ramificações nas representações coletivas de nossa sociedade, com vistas a combater uma visão mítica, elitista e excludente em leitura.

Os estudos que vão nessa direção possuem uma contribuição inquestionável no campo da leitura, sendo extremamente atuais, pois nos ajudam a redimensionar e melhor situar esses discursos fatalistas da leitura ou da ausência de leitura entre os jovens e na sociedade brasileira de modo geral. Porém, é preciso também olhar com cuidado o modo como essas pesquisas acadêmicas, preocupadas em empreender as práticas de leituras cotidianas e combater as desigualdades que as circundam, foram incorporadas e até mesmo distorcidas pelo discurso pedagógico, inclusive em muitos livros didáticos. Estes, nos últimos tempos, cada vez mais, passaram a incorporar textos curtos, de leitura rápida e instantânea, promovendo uma certa relativização e afrouxamento na caracterização de certos textos, mais densos e complexos em relação a outros de cunho midiático, mais simplificados e instantâneos, colocando-os, não raras vezes, dentro de um mesmo conjunto, levando a certa perda de suas categorizações e especificidades no âmbito pedagógico. Isso motivado pelo objetivo de agradar e incentivar sua leitura por alunos e professores, como se a leitura sempre fosse ou tivesse que ser prazerosa, o que pode ser prejudicial se acaba reforçando apenas o já sabido, dando mais do mesmo e dificultando uma formação leitora crítica e emancipatória do sujeito, fundamental na construção de uma sociedade mais justa, humana e igualitária (CURCINO, 2014).

Frente ao exposto, observamos que durante décadas o discurso da leitura e do leitor no Brasil foi predominantemente o da negação, entre tantas outras razões, por não haver uma identificação e reconhecimento cultural dos brasileiros com certas práticas e representações de leituras hegemônicas. Porém, essa concepção, ao menos entre o público juvenil, vem sofrendo mudanças, seja em função dos jovens estarem lendo cada vez mais (CECCANTINI, 2016, 2009) ou talvez por uma maior relativização na validação e legitimação de certas leituras que antes não eram declaradas ou contabilizadas. Com base em vários estudos da área, mas também em pesquisas e dados empíricos que temos empreendido desde 2014, pudemos constatar que tem ocorrido mudanças no que os jovens compreendem por leitura e por ser leitor, logo, na forma como se declaram ou não como leitores, a partir de quais princípios, justificativas e representações.

Sendo assim, a seguir, nos valemos de dados gerados em 2018, via questionários, respondidos por 101 alunos e também entrevistas realizadas com 20 estudantes, todos eles da Escola Agrícola de Jundiaí, da Universidade Federal do Rio Grande do Norte (EAJ/UFRN). Nossa intenção é ilustrar e analisar como essas flutuações e relativizações discursivas têm ocorrido naquilo que enunciam os jovens sobre si como leitores e da 
leitura de modo geral, sinalizando uma possível transformação contemporânea pela qual passam esses discursos.

\section{Declarações valorativas de jovens acerca da leitura e de si como leitores}

"A utilização do livro por pessoas privilegiadas o estabelece como um segredo do qual somente eles são os 'verdadeiros' intérpretes". (CERTEAU, 1996, p. 267).

A leitura, como discutimos em alguns momentos deste artigo, está imbricada por discursos que envolvem relações de classe e de poder, refletindo diretamente no que entendemos por ser leitor e, mais ainda, um bom leitor na contemporaneidade. Essa figura se constitui de modo bastante complexo ao longo do tempo e relaciona-se a uma série de representações, próprias das transformações discursivas, da sua "rarefação, mas também de reagrupamento e de unificação dos discursos [...] sua formação ao mesmo tempo dispersa, descontínua e regular" (FOUCAULT, 2014, p. 61-62).

Na perspectiva de Certeau (1996), a elitização em leitura poderia ser revista mediante uma concepção plural de leitura, que motive a liberdade do leitor, funcionando como uma arma cultural de embate a essas relações de poder social. Porém, ainda assim, se considerarmos o contexto brasileiro, com desigualdades sociais tão alarmantes e acentuadas, cabe a questão "Quem sabe ler e pode ser leitor no Brasil ainda hoje?", que não, por muito tempo e exclusivamente, salvo raríssimas exceções, a elite, com condições materiais, intelectuais e de tempo para ler. São eles, ainda nos dias de hoje, que entoam suas vozes no domínio dos sentidos, impedindo a qualquer outra que tente subverter esse sistema, de que já de partida não saia em desvantagem. Contudo, ainda em desvantagem, essas vozes outras tem emergido cada vez mais.

Nosso objetivo, com os dados a seguir, é mostrar como esses discursos ora são reiterados, ora subvertidos pelos jovens participantes da presente pesquisa, evidenciando possíveis descontinuidades e rarefações em determinados consensos acerca da leitura e do ser leitor, que vem ocorrendo nesse campo discursivo. Essa flutuação discursiva pode corroborar no desenvolvimento de uma concepção menos elitista e mais plural da leitura. Com isso em vista, em nossas análises usaremos simultaneamente dados dos questionários e das entrevistas, sempre marcando e diferenciando cada um deles, com a intenção de construir uma análise progressiva, que se inicia pela reiteração dos consensos em leitura, por parte desses jovens e a negação de si como leitores, passando pela sua subversão, a partir de uma maior relativização das práticas, formas de ler e dos gêneros lidos, que termina por culminar no reconhecimento e declaração de boa parte desses jovens como bons leitores. 
A começar pelo questionário, ao perguntarmos aos 101 entrevistados, a partir de uma questão de múltipla escolha, em que podiam marcar mais de uma opção, representações que entendiam serem fundamentais a um bom leitor, chegamos ao seguinte gráfico?:

Gráfico 1. Quais são as práticas essenciais a um bom leitor

101

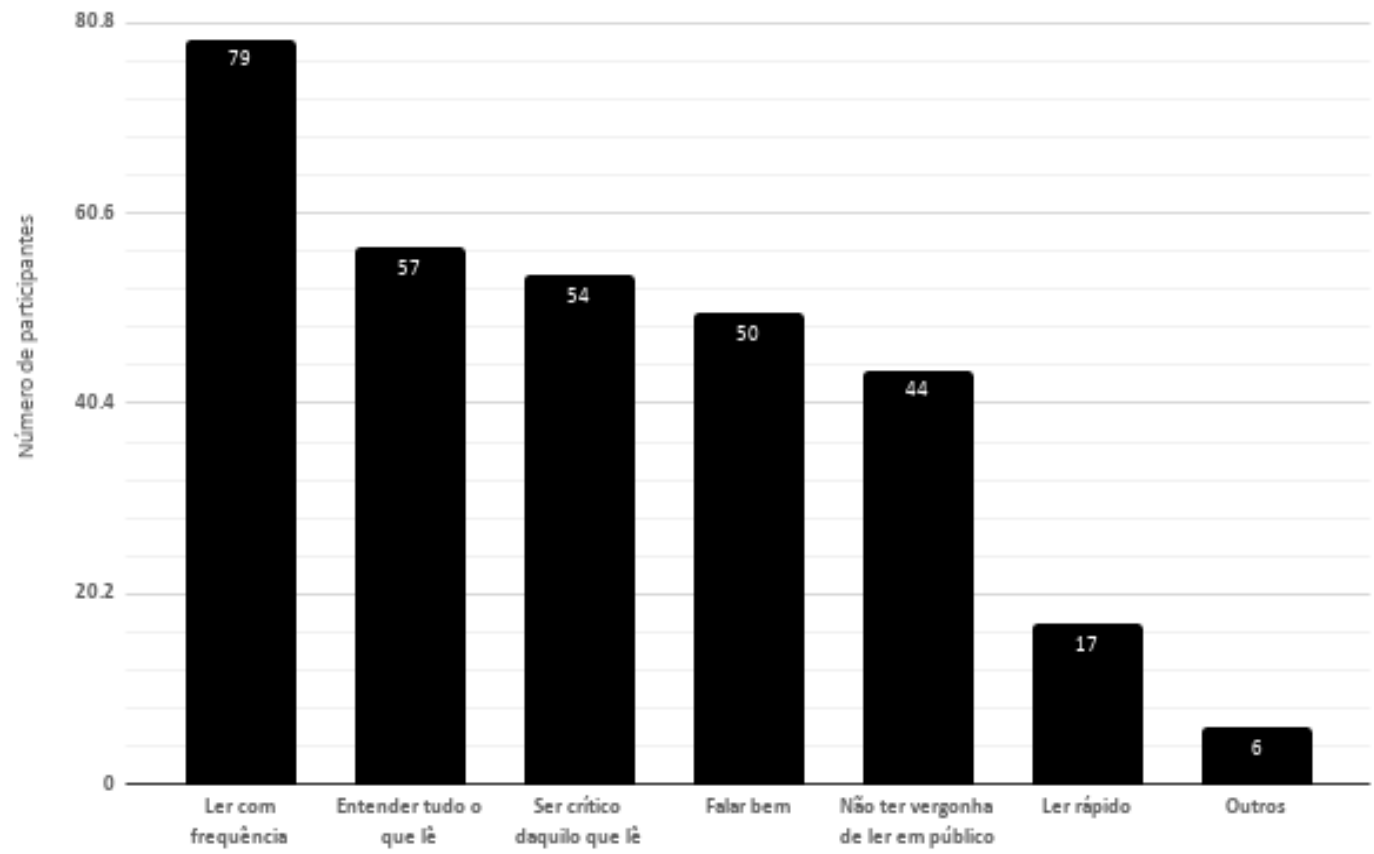

Fonte: Coleta de dados do autor

Para 79 (78,2\%) dos participantes, um bom leitor é aquele que lê com frequência, ou seja, a leitura como hábito, o que implica, como princípio básico, não apenas o acesso fácil e contínuo a bens materiais de leitura, mas também a disponibilidade de tempo para a sua realização, sendo este um bem bastante precioso na contemporaneidade, principalmente do tempo ocioso, o qual poucos possuem. Paralelamente a isso, em outro momento do questionário, em dados gerais, a falta de tempo é declarada por $50(49,5 \%)$ desses jovens

7 As opções de escolha se deram por algumas delas serem recorrentes na $4^{\mathrm{a}}$ e $5^{\mathrm{a}}$ edição das pesquisas Retratos da Leitura no Brasil (2016 e 2019) e também pelos nossos objetivos de pesquisa, entre os quais, compreender o modo como acreditam que se deve ler e as habilidades/ quesitos que consideram necessárias para ser um bom leitor, em que medida reforçam ou não certos consensos. 
como a principal dificuldade para a realização de leituras. Este último dado dialoga com os resultados da $5^{a}$ pesquisa Retratos da Leitura no Brasil, desenvolvida em 2019, em que a razão mais frequente entre os não leitores ${ }^{8}$ para não terem lido nos últimos três meses é a falta de tempo (34\%) ou entre os leitores para não terem lido mais (47\%). Isso significa, no imaginário comum desses jovens, que para ser leitor é preciso ler com frequência, diária ou semanalmente; logo, é preciso ter o que declaram Ihes faltar, tempo, uma vez que não consideram as leituras escolares e com finalidades técnicas como legítimas.

Na parte aberta do questionário, ao serem interpelados sobre "O que você considera ser um bom leitor?", ler com frequência aparece com certa regularidade, mas passa a compartilhar espaço semelhante com outras representações, como vemos na resposta de Al03 em que um bom leitor seria aquele "[...] que lê frequentemente, não por obrigação ou por necessidade, por prazer. Alguém que sempre está buscando novas obras da(s) sua(s) área(s) de interesse". A questão da frequência em leitura é reafırmada, mas acrescida da exigência de que seja feita por prazer, já que, segundo AI03, a leitura por necessidade ou obrigação não produziria o mesmo efeito. Ao longo das respostas acrescentam outros requisitos para ser um bom leitor, que realize grandes quantidades de leitura, que sejam diversas, mas sem perder a criticidade em leitura e um entendimento total dos textos, buscando conhecimentos, a partir de coisas interessantes.

No que tange às entrevistas realizadas com 20 estudantes participantes de um grupo de leitura escolar, as referências de um bom leitor, entre 14 (70\%) dos declarantes, reforçam esses discursos consensuais sobre a leitura, a título de exemplo, segundo E20 um bom leitor é aquele que "leve a sério (a leitura) [...] que determine um tempo, que tenha uma organização para ler, assim, meio que diariamente" (grifos nossos).

Partindo dessas representações, as exigências para ser um bom leitor são tão grandes, que necessitaria ser uma profissão, frente às demandas de tempo que atender a esse ideal de leitor exigiria e, ainda assim, cabe a questão: seria possível se tudo isso fosse levado ao "pé da letra", ler tanto tempo, com tantas exigências e sempre por/com prazer? Reconhecer esses imaginários em leitura permite-nos entender os mecanismos que fundamentam a sua elitização, fomentando na prática a institucionalização da leitura e do ser leitor como direito e possibilidade de poucos, a partir de uma visão um tanto mítica do tema.

Por outro lado, uma boa parte desses jovens relativiza esses consensos, na parte aberta do questionário, por exemplo, AP21 declara que "Todo mundo é um bom leitor. O que falta é apenas praticar mais esse hábito" (grifos nossos). Esse sujeito, ignorando as hierarquias

8 Segundo a metodologia assumida pela pesquisa, é leitor aquele que leu, inteiro ou em partes, pelo menos 1 livro nos últimos 3 meses e não leitor aquele que declarou não ter lido nenhum livro nos últimos 3 meses, mesmo que tenha lido nos últimos 12 meses. 
em leitura, talvez por desconhecê-las ou, simplesmente, por não fazer caso delas, acredita que todos sejam bons leitores, relativizando certos consensos em leitura, ao mesmo tempo em que reconhece a importância da frequência na formação leitora, como fator decisivo no desenvolvimento e definição de um perfil leitor.

Nas entrevistas, E15 declara: "você define o que é um bom leitor. Porque cada um tem suas condições de leitura [...] eu não vejo que a questão de ser um bom ou mal leitor tem a ver com a frequência ou então com a quantidade de livros" (grifos nossos). E15 ao afirmarse como bom leitor não só pondera sobre alguns consensos em relação à construção mais prototípica de um bom leitor, como nega a frequência e a quantidade de livros lidos como fator determinante para isso. Atribui ao leitor o papel e o poder exclusivo de decisão sobre o assunto, concebe a prática da leitura como um processo subjetivo, relacionado à singularidade do sujeito, em que caberia a ele avaliar suas possibilidades e condições de poder ler e ser um bom leitor, como conhecedor de sua história de vida e em leitura.

Possivelmente a afirmação de que "cada um tem suas condições de leitura" se deva, entre outras coisas, ao reconhecimento do aluno de seu entorno escolar, de um contexto plural, em que as realidades sociais e econômicas são bastante diversas, bem como da disponibilidade de horários vagos que cada estudante possui, de acordo com a especificidade de sua formação técnica. Na sequência, E15 se compara ao colega de outra área à sua "[...] por exemplo, eu só tenho aquele horário para ler [...] e E16 pode ter um tempo a mais do que eu". Essa perspectiva de E15 acerca das diferenças de condições em leitura se acentuaria ainda mais se olhássemos para o cenário nacional, em que muitos convivem diariamente com a falta do essencial para a manutenção saudável do próprio corpo, alijados completamente de qualquer possibilidade efetiva de que a leitura e o ser leitor sejam cultivados de maneira perene e como algo natural ao longo da vida, já que muitas vezes não têm nem mesmo a oportunidade de acesso a uma educação formal.

Enunciados semelhantes ao de E15 emergem em outros dois grupos de entrevistas, a partir do que declaram três participantes:

"Para mim, ser bom leitor é ler o que você gosta, é você continuar fazendo o que te faz bem, o que te faz feliz, não adianta você pegar uma ruma de livros, ler tudinho. [...] é ler e somar na sua vida" (E03, grifos nossos)

"Eu me considero um bom leitor, mas se for ver pelo lado do que foi dito aqui, eu sou um péssimo leitor. Todos os defeitos que vocês falaram aí eu tenho, mas ainda assim eu me considero um bom leitor, porque eu acho que a única coisa que torna um bom leitor é o que [...] acrescenta na vida da pessoa" (E02, grifos nossos)

"Eu acho que eu sou uma boa leitora. Eu não leio tantos livros, mas o que eu leio eu acho que eu absorvo, que esse é o meu intuito. E eu acho, leitura é isso, você ter prazer em fazer as coisas e eu acho que não precisa ser tão cronometrado: '- Ah, vou ler todos os dias, uma parte do dia"'. (E19, grifos nossos) 
Esses quatro entrevistados (E15, E03, E02 e E19) foram os que se declararam serem bons leitores e compartilham do princípio de que para sê-lo não é preciso ler muito e todos os dias ou toda semana. Eles concebem a leitura e a sua prática no âmbito da individualidade, ainda que a reforcem como fonte de prazer e bem-estar, relativizam os gêneros e as formas de ler, em que práticas e objetos distintos são igualmente valorizados. O que prevalece em suas declarações é o modo como o lido se insere e acrescenta nas suas vidas, isto é, a leitura segue sendo considerada como um meio de agregar valores à vida e à imagem do indivíduo, mas é discursivamente priorizada enquanto prática subjetiva e singular.

E02, o último a responder à questão dentro de seu grupo, sobre ser um bom leitor, afirma: "Eu me considero um bom leitor, mas se for ver pelo lado do que foi dito aqui, eu sou um péssimo leitor" (grifos nossos). Por ter sido o último a responder, E02 goza de uma posição privilegiada de análise e comparação com as demais respostas declaradas pelos seus colegas, o que lhe permite estabelecer cotejamentos com as declarações anteriores. Em geral, os que respondem antes de E02 e não se veem como bons leitores, justificam não ser por causa do cansaço, da falta de interesse ou preguiça em ler livros mais volumosos e densos, falta de vontade em buscar temas e leituras novas aos que comumente leem, sem contar a falta de tempo, ocupado em boa parte pelas demandas e exigências da escola em tempo integral. É interessante observar que E02 afirma sentir todas essas sensações e realizar essas práticas que fogem a um ideal de "bom leitor" e, ainda assim, se reconhece enquanto um "bom leitor", para além desse ideal, pois o que pesa sobre o seu posicionamento é a singularidade de suas leituras e das experiências que vivência com e por meio delas.

Os consensos em leitura também são parcialmente negados por E19, que não só afirma não ler tantos livros, mas também defende que a leitura não deve ser cronometrada, como uma tarefa diária. Por fim, termina se afirmando como um "bom leitor" pelas mesmas razões que os demais que se posicionam assim, a da experiência individual desenvolvida e vivenciada por essa prática, fazendo com que os outros discursos e consensos que poderiam intimidá-los ou convencê-los de que não são bons leitores, como ocorreu com a maioria dos entrevistados, se tornem secundários.

No entanto, todas essas afirmações de recusa de vários consensos em leitura ao falarem de si como "bons leitores", não se dá sem certas modalizações, no caso o uso de pronomes que marcam a primeira pessoa do singular, que coloca em voga o "essa é a minha opinião", como um argumento implícito a possíveis censuras, seja dos colegas ou do próprio pesquisador. Ainda que seja uma pergunta de caráter pessoal, não necessariamente implica a constante reiteração da primeira pessoa do singular "Para mim", "Eu me considero", "eu acho", este último só na parte que destacamos do que declara E19 aparece quatro vezes, o que mostra um certo cuidado desses estudantes ao se contraporem aos consensos em leitura. 
Esses diferentes discursos ora se aproximam, ora se distanciam dos consensos em leitura, oscilando e intercalando no que enunciam esses estudantes. A separação que fizemos aqui tem finalidades metodológicas e didáticas, pois na prática eles se dão de forma imbricada, gerando embates, contradições e lutas pelo domínio dos sentidos no que se entende por leitura, ser leitor e bom leitor.

Pudemos constatar que a aproximação e identificação dos estudantes a um discurso mais elitista e consensual sobre as práticas de leitura contribui a que 42 (41,5\%) dos participantes do questionário e 14 (70\%) dos entrevistados não se reconheçam ou não se declarem como bons leitores. Em contraposição àqueles que possuem uma maior afinidade com esses discursos mais relativizados sobre a leitura e o ser leitor, tendem mais facilmente a se reconhecerem como bons leitores, no caso foram 4 (20\%) dos entrevistados e 59 (58,4\%) dos participantes do questionário. Por fim, 2 (10\%) dos entrevistados disseram não saber responder à questão.

Em geral, a maioria desses alunos leem não só em sala de aula, objetos e leituras pragmáticas, com finalidades específicas, como também declaram ler todo dia ou toda semana fora do contexto de sala de aula, leituras de fruição e por prazer, ou seja, eles leem muito e o tempo todo. Esse reconhecimento ou não de ser um bom leitor está mais relacionado com as representações que fazem sobre o tema e com a afinidade que possuem ou não em ocupar esse lugar-sujeito, do que efetivamente com as leituras que declaram realizar diariamente.

Essas relativizações em leitura, inclusive por sujeitos de origem simples e em situação de vulnerabilidade social, ao se reconhecerem como leitores, um lugar historicamente ocupado, quase sempre, por uma minoria elitizada de nossa sociedade, detentores de condições materiais, intelectuais e de tempo para isso, sinaliza novas formações discursivas sobre o tema. Nesse âmbito, o nosso desafio como professores, seja na formação de jovens leitores ou na formação de docentes que também formarão leitores, deve ser o de encontrar a justa medida de entrada em meio a esses discursos, com o intuito de promover uma formação crítica do sujeito. Uma formação nesse viés permite aos alunos não apenas se reconhecerem como leitores, mas também as hierarquias e as coerções históricas que envolvem o tema, com a finalidade de subvertê-las na construção de uma sociedade mais democrática, inclusive, na distribuição e no acesso ao conhecimento.

\section{Conclusão}

Trabalhos que nos ajudam a entender a história da leitura no Brasil, muitas vezes, corroboram para a própria compreensão da organização de nossa sociedade, suas hierarquias desiguais, bem como uma elitização histórica de acesso limitado a um certo capital cultural de prestígio, que tem servido há décadas à desqualificação e inferiorização 
das classes menos favorecidas, quando não Ihes destitui de direitos básicos. Que os jovens tenham acesso a um ensino público de qualidade, principalmente jovens em situação de vulnerabilidade social, é um passo imprescindível na construção de uma nação mais justa, humana e igualitária. É interessante observar, por meio de nosso corpus, como o acesso desses estudantes à Escola Agrícola de Jundiaí (EAJ), principalmente entre os mais humildes, tem mudado a concepção que fazem sobre si e sobre a leitura, logo sobre a forma como entendem a sociedade e as suas engrenagens de funcionamento.

Por outro lado, em parte de nossos dados, pudemos observar a recorrência de enunciados que insistem em atestar a ausência da leitura na vida dos próprios entrevistados, jovens em fase escolar, com acesso a um ensino público de qualidade e que estão cotidianamente realizando uma extensa e intensa carga de leitura formativa. O que coloca em evidência a força e a reminiscência de certos discursos, que oprimem até mesmo aqueles que os enunciam e os tomam por verdade, neste caso os alunos que não apenas negam a leitura por diferentes formas, mas a si como leitores, logo a condição de poder sê-lo, como algo já no campo do naturalizado. Tal naturalização contribui para o apagamento do fato de que o acesso à informação crítica e ao ser leitor deveria ser direito básico de qualquer cidadão brasileiro e mesmo quando o é, ainda assim, em certos casos, persiste a negação, colocando a leitura, o seu acesso e o ser leitor como algo no campo do inalcançável para os mais humildes.

Frente ao exposto, esse cenário de certas contradições discursivas se apresenta para nós não só como uma complexa arena de lutas pela valoração e calibragem dos sentidos, mas também como um lugar de possíveis mudanças nas concepções daquilo que os jovens declaram e entendem sobre a leitura e de si como leitores, logo, do lugar que ocupam e desejam ocupar dentro desse cenário. Mas o que nos parece mais importante é o empoderamento que o reconhecimento e a afirmação de si como leitor pode permitir aos estudantes, principalmente os de origem mais simples, a partir da tomada de consciência dos seus direitos de ser e do seu papel na sociedade, em subverter a elitização do conhecimento como processo e parte da construção de uma sociedade mais livre, humana e justa.

\section{Agradecimentos}

O presente trabalho foi realizado com apoio da Coordenação de Aperfeiçoamento de Pessoal de Nível Superior - Brasil (CAPES) - Código de Financiamento 001. Advém de uma pesquisa de doutorado realizado no âmbito do Programa de Pós-graduação em Linguística da Universidade Federal de São Carlos, orientada pela Profa. Dra. Luzmara Curcino e coorientada pelo Prof. Dr. Daniel Cassany. 


\section{REFERÊNCIAS}

ABREU, M. Diferença e Desigualdade: Preconceitos em Leitura. In: MARINHO, M. (org.). Ler e Navegar: espaços e percursos da leitura. Campinas: Mercado de Letras, ALB, 2001. p. 139-157.

BORGES, R. R. S. Formando leitores no ensino de outra língua: uma análise de representações de leitura compartilhadas por professores de língua espanhola. 2017. Dissertação (Mestrado em Linguística) - Centro de Educação e Ciências Humanas, Universidade Federal de São Carlos, São Carlos, 2017.

BRITTO, L. P. L. Máximas impertinentes. Na Ponta do Lápis, São Paulo, n. 27, p. 32-39, 2016. Disponível em: https://www.escrevendoofuturo.org.br/arquivos/5917/npl2703ago2016.pdf. Acesso em: 03 jun. 2020.

CASSANY, D. Tras las lineas: Sobre la lectura contemporánea. Barcelona: Anagrama, 2006.

CECCANTINI, J. L. Mentira que parece verdade: os jovens não leem e não gostam de ler. In: FAILA, Z. (org.). Retratos da Leitura no Brasil 4. Rio de Janeiro: Sextante, 2016. p. 83-98.

CECCANTINI, J. L. Leitores iniciantes e comportamento perene de leitura. In: SANTOS, F. et al. (org.). Mediação de leitura: discussões e alternativas para a formação de leitores. São Paulo: Global, 2009. p. 207-231.

CERTEAU, M. Ler: uma operação de caça. In: CERTEAU, M. A invenção do cotidiano. Tradução Ephraim Ferreira Alves. 2. ed. Petrópolis: Vozes, 1996. p. 259-273.

CHARTIER, R. A aventura do livro: do leitor ao navegador. Tradução Reginaldo de Moraes. São Paulo: Editora UNESP, 1999.

CHARTIER, R. A História Cultural: entre práticas e representações. Tradução Maria Manuela Galhardo. Lisboa: Difel, 1990.

CURCINO, L. Desafios ao ensino de leitura frente às ordens que regulam sua produção na atualidade. In: MOMESSO, M. R. et al. (org.). As práticas do ler e escrever: ao universo das linguagens, códigos e tecnologias. Porto Alegre: CirKula, 2014. p. 45-62.

FAILLA, Z. Retratos da leitura no Brasil 4. São Paulo: Instituto pró-livro, 2016. Disponível em: http://prolivro.org.br/home/images/2016/RetratosDaLeitura2016_LIVRO_EM_PDF_ FINAL_COM_CAPA.pdf. Acesso em: 15 jul. 2020. 
FOUCAULT, M. A arqueologia do saber. Tradução Luiz Felipe Baeta Neves. Rio de Janeiro: Forense Universitária, 2015.

FOUCAULT, M. A ordem do discurso: aula inaugural no Collège de France, pronunciada em 2 de dezembro de 1970. 24. ed. São Paulo: Edições Loyola, 2014. p. 74.

PETIT, M. Os leitores não deixam de nos surpreender. In: PETIT, M. Leituras: do espaço íntimo ao espaço público. São Paulo: Editora 34, 2013. p. 21-29.

SOARES, M. As condições sociais da leitura: uma reflexão em contraponto. In: ZILBERMAN, R. et al. (org.). Leitura: perspectivas interdisciplinares. São Paulo: Ática, 2001. p. 18-29. 